\title{
Determinants of Rural Households' Poultry Chicken Breeds Choice in Wolaita, Ethiopia
}

\author{
Berhanu Kuma ${ }^{1}$ and Girma Gata ${ }^{2}$ \\ ${ }^{1}$ Department of Agricultural Economics, Wolaita Sodo University, P O Box 138, Wolaita \\ Sodo,Ethiopia, berhanukuma@yahoo.com Mobile:+251911352296. \\ ${ }^{2}$ Department of Agricultural Economics, Wolaita Sodo University, P O Box 138, Wolaita \\ Sodo, Ethiopia, girmagganebo@gmail.com.
}

\section{Abstract}

To achieve increased productivity in poultry chicken, households' choice of poultry chicken breeds should be maintained according to their desirability. This study aimed at identifying determinants of rural households' choice of poultry chicken breeds keeping in Wolaita, Ethiopia. Multistage sampling techniques were used. First, Damot Pulasa district was selected purposively because of high poultry production potential, and then simple random sampling technique was used to select five kebeles and at third stage systematic random sampling was used to select 160 rural households. Data were collected through interview schedule and analyzed using descriptive statistics and econometric regression. Result showed that $54.37 \%$ of households owned indigenous poultry chicken breed, $38 \%$ owned exotic poultry chicken breeds and $7.63 \%$ owned both indigenous and exotic poultry chicken breeds. Households attached socioeconomic, demographic and institutional factors and breed related traits to their poultry chicken breed choices. Indigenous chicken breeds were preferred in mothering ability, disease resistance, scavenging ability; taste of meat and egg traits whereas exotic poultry chicken breeds were preferred for growth rate, productivity and total eggs laid per chicken per year. In addition, Multinomial Logit model result indicated that age and education level of household head determined poultry chicken breed choice. To be effective and efficient any poultry chicken breed promotion effort in the future should consider these particular preferences of households.

Keywords: Chicken breeds, Choice, Ethiopia, Multinomial logit, Wolaita 


\section{Introduction}

Poultry production is one of the dominant livelihood strategies of rural households in Africa which accounted about $80 \%$ of its population. It contributes to domestic food security (Fulas et al., 2018); as source of income (Padhi, 2016); provision of affordable animal protein (Dessie, 2017) and source of employment (Berhanu, 2020). About 97\% of Ethiopia's poultry chicken was domesticated indigenous chicken and 3\% was imported exotic chicken breed (Fulas et al., 2018). About 95.86\%, 2.79\% and 1.35\% of total national eggs and meats product comes from indigenous breed, hybrid and exotic breed respectively (CSA, 2017).

In order to improve production and productivity of poultry chicken, various attempts have been made during different times through importation of exotic chicken breeds and disseminating to rural households as part of public extension program in the form of poultry extension packages (Tamirat, 2015). Despite these attempts of the governments, the production of exotic poultry chicken is very low due to low adoption by rural farmers. The exotic breed has failed to become part of sustainable production because they did not adapt well to harsh rural production environment and these resulted for high mortality rates during the rainy season (Alemayehu et al., 2015).

On contrary to exotic chicken breeds which are fast growing and productive, rural households keep low productive and slow growing indigenous poultry chicken breed (Wong et al., 2017). The exotic chicken breeds were provided to rural households without having consultation with them and asking them for their preference. Thus rural households did not get opportunity to choose among the alternatives and analyze how, when, where, and under what circumstances they would be productive. In addition, there were no context-specific empirical and documented evidence on chicken breeds production, consumption and rational preferences of ecotypes for policy formulation in Ethiopia (Brown et al., 2017).

The inappropriate poultry chicken promotion without taking into account the rural households' demographic, socioeconomic and institutional characteristics and chicken breed related traits led to failure of their performance in various agro-ecology of the 
country (Nigussie et al., 2010). The importation of exotic chicken breeds was not empirically supported by their adaptability and management needs in comparison with high diversity of indigenous chicken in Ethiopia (Psifidi et al., 2016). The diversity of the non-descriptive breeds and genetic traits variability is important to set the best choice of chicken breeds with their respective agro-ecologies (Adebambo et al., 2018) though the selection of breeding and genetic preferences is complex processes (Tlou et al., 2020).

Empirical findings indicated that breed choices were separately analyzed for exotic chicken breeds (Simegnew, 2019), indigenous chicken breeds (Berhanu et al., 2020; Yacubu et al., 2019; Tlou et al., 2020; Zelalem et al., 2020; Nigussie, 2011; Fekadu, 2019). In terms of methodology, the findings were analyzed using descriptive statistics for comparison and lacked econometric models (Nigussie et al., 2011). Study conducted by Zelalem et el (2019) and Habte (2019) used generalized linear econometric model and Berhanu et al (2020) used generalized multinomial logit econometric model. However, this study is noble in its approach because it holistically analyzed rural household poultry chicken breed choice as the interaction of household demographic and socioeconomic characteristics, institutional characteristics and chicken breeds related characteristics using multinomial logit model. The objective is to identify determinants of rural households poultry chicken breeds choice in Ethiopia.

\section{Materials and Methods}

\subsection{Description of the Study Area}

Damot Pulasa district is found in Wolaita zone, Ethiopia which covers an area of $165 \mathrm{~km}^{2}$. It lies approximately between $6.97^{0}-7.11^{0}$ North latitude and $37.78^{0}-37.94^{0}$ East longitude and experiences full of Woina-Dega or moderate ecology. It has a population of 166,384 and settled in one urban and 22 rural kebeles (WoFED, 2020). Damot Pulasa district is known by large number of livestock, comprising cattle 120,000, sheep 23,089, goat 2463 , poultry chicken 200,337 and equine 3,545 (WoFED, 2020). The district is one of the $4^{\text {th }}$ potential areas of the zone in poultry chicken population followed by Duguna Fango $(297,836)$, Boloso Sore $(289,998)$ and Kindo Didaye $(218,055)$ districts (WoFED, 2020). The indigenous poultry chicken in the district is 125,684 and that of exotic poultry 
population is 74,653 . The institutional constraints such as insufficient number of animal clinics as well as lack of research and market distortions were prominent (WoFED, 2020).

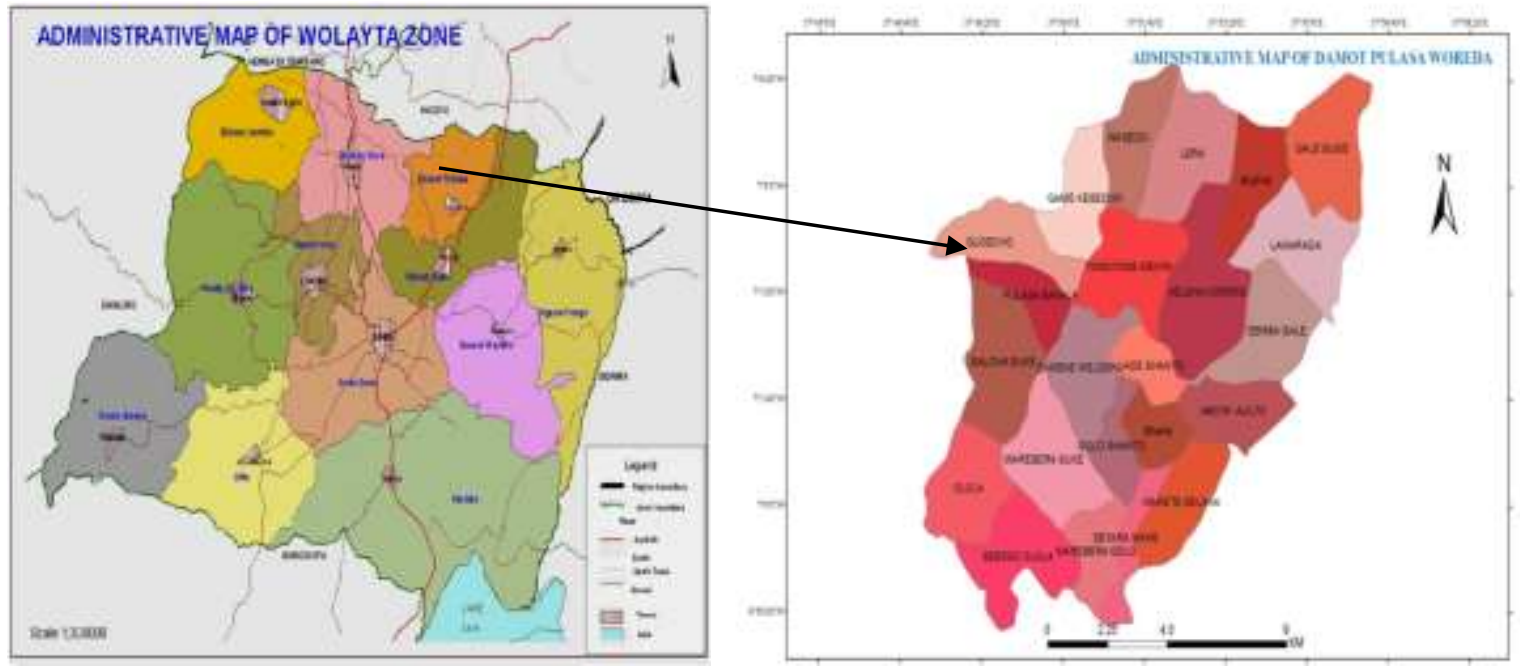

\section{Figure2.1Administrative Map of Damot Pulasa District}

\subsection{Sources and Types of Data}

Qualitative and quantitative data were collected from both primary and secondary sources. Primary data were collected from 160 rural households, focus group discussion and key informants interview. To supplement the primary data, secondary data such as theoretical and empirical literature review were obtained from the zonal departments, district offices of livestock and fishery resources, economic development offices and journals.

\subsection{Sample Size Determination and Sampling Techniques}

The sample size was determined by small sample size formula of hyper geometric (Evan Morris, 1998) as given below.

$$
\mathrm{n}=\frac{\mathrm{NZ} \mathrm{Z}^{2} \mathrm{p}^{* \mathrm{q}}}{\mathrm{e}^{2}(\mathrm{~N}-1)+\mathrm{Z}^{2} \mathrm{p}^{*} \mathrm{q}}
$$

Where: $\mathrm{n}$ - Sample size, $\mathrm{N}$ - population size, e- error term $=7 \%$, Z- levels of confidence $(95 \%), \mathrm{z}$ is set to $1.96, \mathrm{p}=0.5$ and $\mathrm{q}=0.5$ were the population proportions.

$\mathrm{n}=3797 * 1.96^{2} * .25 / 0.07^{2}(3797-1)+1.96^{2} * 0.25=160$ households

Multistage sampling techniques were used in the selection of representative sample from households. In the first stage Damot Pulasa district was selected purposively among the districts in Wolaita zone because of high poultry production potential. In the next stage, 
simple random sampling technique was used to select 5 kebeles from 23 kebeles of the district and finally systematic random sampling technique was used to select 160 households. Finally probability proportion to size was used to selected samples from each kebele as given in Table 1.

Table 1. Proportionate sample size of households

\begin{tabular}{llll}
\hline No & Name of Kebele & Total population & Sample households \\
\hline 1 & Golo Shanto & 786 & 33 \\
2 & Ade Shanto & 168 & 7 \\
3 & Zamine Wulshio & 1,294 & 55 \\
4 & Tomteme Menta & 924 & 39 \\
5 & Siyara Mahe & 626 & 26 \\
\hline Total & $\mathbf{3 , 7 9 8}$ & $\mathbf{1 6 0}$ \\
\hline
\end{tabular}

\subsection{Data Collection Methods}

A semi-structured questionnaire was developed, pretested and interviewed. During the interviews, efforts were made to collect information from rural households' head engaged in poultry chicken breeds keeping. Training on questionnaire was given to ten enumerators and data were collected from February to March, 2021 with close supervision by the researchers. The collected data were inputted into SPSS version 25 and imported to STATA version 17 for analysis. In addition, focus group discussion and key informants interview were conducted using checklist with five groups composed of seven male and three female to rank the traits of poultry chicken using pairwise ranking charts.

\subsection{Methods of Data Analysis}

Descriptive analysis such as ratios, tabulation, mean, standard deviation and statistical tests were used to describe the variables. Multinomial Logit econometric model was used to identify determinants of rural households' poultry chicken breeds choices.

\section{Specification of Multinomial Logit Model}

Multinomial Logit model was applied to identify determines of rural households' choice of poultry chicken breeds keeping that can provide maximum utility. This utility is modeled as a function of individual specific characteristics, intuitional characteristics and chicken 
related traits, $X$, that affect the utility associated with each choice differently and indirectly. Hence,

$\mathrm{U}_{\mathrm{ij}}=\mathrm{X}_{\mathrm{ij}}+\varepsilon_{\mathrm{ij}}$

Where, subscript $\mathrm{j}$ denotes the choice and subscript $\mathrm{i}$ denotes the individual.

The probability distribution of $\mathbf{Y}_{\mathbf{i} \mathbf{j}}$ is defined as

$\operatorname{Pr}\left(y_{\mathrm{ij}}=\mathrm{j} / \mathrm{X}_{\mathrm{ij}}\right)=\left(\exp ^{\mathrm{xij} \beta \mathrm{j}}\right) / \sum_{i=0}^{j}(\exp \mathrm{xij} \beta \mathrm{j})$

Where, $\mathbf{X}_{\mathbf{i j}}$ is the vector of explanatory variables; $\mathbf{i}^{\text {th }}$ households facing $\mathbf{j}$ alternatives and $\boldsymbol{\beta}_{\mathrm{ij}}$ is the vector of regression coefficients associated with alternative $\mathbf{j}$.

Following the above equation, fitting of the multinomial logit model for this study as follows:

$\operatorname{Pr}\left(\mathrm{CHOICE}_{\mathrm{ij}}=\mathrm{j}\left(\exp ^{\mathrm{xij} \beta \mathrm{j}}\right) / \sum_{i=0}^{2}(\exp \mathrm{xij} \beta \mathrm{j})\right.$ forj $=0,1,2 \ldots$

Where, $\boldsymbol{i}$ - represents $\boldsymbol{i}^{\text {th }}$ households, and $\boldsymbol{i}=\mathbf{0}, \mathbf{1}, \ldots, \mathbf{n} ; \mathbf{j}$ - represents types of poultry chicken breeds $(\mathbf{j}=\mathbf{0}$ indigenous poultry chicken breed; $\mathbf{j}=\mathbf{1}$ exotic poultry chicken breed $=\mathbf{2}$ both poultry chicken breeds). $\boldsymbol{P}$ - The probability of a family having poultry breeds $\mathbf{j}$ and to be chosen by rural households $\mathbf{i}$; $\boldsymbol{C H O I C E}_{i j^{-}}$means that poultry chicken breeds keeping $\mathbf{j}$ is chosen by household head $\boldsymbol{i}$. For a dummy variable with $\mathbf{M}$ categories $(\mathbf{M}=\mathbf{3})$, this requires the calculation of 3-1 equations, one for each category relative to the base category to describe the relationship between the predictors and the category variable. To identify the model $\boldsymbol{\beta}$ 's for one of the outcomes will be set to be equal to zero to reflect normalization (Greene, 2018). The most popular and simplest technique of selection of the base category is the alternative with the most number of observations; in this study the indigenous poultry chicken breed.

Setting $\boldsymbol{\beta}(\mathbf{1})=\mathbf{0}$, the equations become

$\operatorname{Pr}\left(\mathrm{y}_{\mathrm{ij}}=0 / \mathrm{X}_{\mathrm{ij}}\right)=1 / 1+\sum_{i=1}^{2}\left(e^{X i j B j}\right)$.

$\operatorname{Pr}(\mathrm{y}=0)=1^{\prime} 1+\mathrm{e}^{\mathrm{X} \beta(1)}+\mathrm{e}^{\mathrm{X} \beta(2)}$

$\operatorname{Pr}\left(y_{\mathrm{ij}}=\mathrm{j} / \mathrm{X}_{\mathrm{ij}}\right)=\left(\mathrm{e}^{\mathrm{xij} \beta \mathrm{j}}\right) / 1+\sum_{i=1}^{2}\left(e^{X i j B j}\right)$ for $\mathrm{j}=1,2$.

$\operatorname{Pr}(\mathrm{y}=1)=\mathrm{e}^{\mathrm{X} \beta(1)} / 1+\mathrm{e}^{\mathrm{X} \beta(1)}+\mathrm{e}^{\mathrm{X} \beta(2)}$

$\operatorname{Pr}(\mathrm{y}=2)=\mathrm{e}^{\mathrm{X} \beta(2)} / 1+\mathrm{e}^{\mathrm{X} \beta(1)}+\mathrm{e}^{\mathrm{X} \beta(2)}$ 
According to Greene (2003), Multinomial Logit coefficients are difficult to interpret and associating with the $\mathbf{j}^{\text {th }}$ outcome is attractive and misleading. So, the log odd ratio and the odd ratio interpretation were used to interpret the relationship and the direction between both comparison variables and base category. For categorical predictor variables, it represents the odds ratio between groups and for continuous predictor variables, it represents the odds ratio between individuals who are identical on the other variables but differ by one unit on the variable of interest. The estimated odds ratio (OR) is given as:

$\mathrm{OR}=\underline{\mathrm{Odds}} 2$

$$
\operatorname{Odds}_{1}=e^{B k X k}-e^{B k(X k+1)}=e^{B k}
$$

Hence when a variable $X_{K}$ increases by 1 unit, with all other factors remaining unchanged, then the odds will increase by a multiplicative factor of $e^{\mathrm{Bk}}$.

By taking the serious consideration of the literature review, insufficient data and small sample size problem the choice of poultry chicken breeds keeping model for this study except the base category can be specified as:

$C H O P=\beta_{0}+\beta_{1} A G E+\beta_{2} S E X+\beta_{3} E D U+\beta_{4} O F F+\beta_{5} R E S+\beta_{6} C O L+\beta_{7} C O M+\beta_{8} G R R+$ $\beta_{9} E G Z+\beta_{10} E G N+\beta_{11} E G C+\beta_{12} M O T+\beta_{13} M T A S+\beta_{14} C R T+\beta_{15} F E D+$ $\beta_{16} \mathrm{HOU}+\beta_{17} \mathrm{HEA}+\beta_{18} \mathrm{PRO}+\varepsilon \mathrm{i}_{j}$

Where, $\beta_{1-} B_{18}$ were coefficients and $\varepsilon_{i j^{-}}$error term.

Table 2. Summary of variable descriptions

\begin{tabular}{lll}
\hline $\begin{array}{l}\text { Variables } \\
\text { Types }\end{array}$ & Description of Variables \\
\hline Dependent variable & \\
CHOP $\quad$ Categorical & Choice of poultry breeds : 0 . Indigenous breed; 1 . Exotic breed; 2 . both breeds \\
Explanatory variables & \\
AGE & Continuous & Age of the household head, measured in years \\
SEX & Dummy & Sex of the household head $(0=$ male; $1=$ female $)$ \\
EDU & Continuous & Years of schooling \\
OFF & Continuous & Off farm income measured in Birr \\
$R E S$ & Categorical & Disease resistance $(0=$ low ; $1=$ medium; $2=$ High ; $3=$ undefined $)$
\end{tabular}




\begin{tabular}{|c|c|c|}
\hline$E G Z$ & Dummy & Egg size $(0=$ Big $; 1=$ small $)$ \\
\hline EGN & Continuous & Total number of egg per year per chicken $(0=$ High $; 1=$ low $)$ \\
\hline$E G C$ & Categorical & Egg color ( $0=$ Red $; 1=$ White) \\
\hline MOT & Categorical & Mother ability $(0=$ low $; 1=$ medium; $2=$ High $; 3=$ undefined $)$ \\
\hline MTAS & Dummy & Meat and egg taste $(0=$ Good; $1=$ Poor $)$ \\
\hline COL & Categorical & Feather $\operatorname{color}(0=$ Red; $1=$ Brown; $2=$ White $; 3=$ Gebsima $; 4=$ Teterma $)$ \\
\hline COM & Dummy & Comb type $(0=$ single $; 1=$ Double $)$ \\
\hline GRR & Dummy & Growth rate $(0=$ low $; 1=$ medium; $2=$ High ; $3=$ undefined $)$ \\
\hline CRT & Discrete & Use of credit ( $0=$ utilize $; 1=$ not utilize $)$ \\
\hline FED & Dummy & Supply Feeding resource $(0=$ yes; $1=$ not $)$ \\
\hline $\mathrm{HOU}$ & Dummy & Existence of chicken house $(0=Y e s ; 1=$ No $)$ \\
\hline$H E A$ & Dummy & Health facilities ( $0=$ there is health service; $1=$ No health services $)$ \\
\hline$P R O$ & Categorical & Productivity level $(0=$ low $; 1=$ medium; $2=$ High $; 3=$ undefined $)$ \\
\hline
\end{tabular}

\section{Result and discussions}

\subsection{Demographic characteristics of households- categorical variables}

About $54.37 \%$ of the households owned indigenous poultry chicken breed, $38 \%$ owned exotic poultry chicken breed and $7.5 \%$ owned both indigenous and exotic poultry chicken breeds. In terms of gender, $87 \%$ of the total, $85 \%$ of indigenous chicken owner households, $88.5 \%$ of exotic chicken owner households and $91.6 \%$ of both exotic and indigenous chicken owner households were males. This indicates that chicken households were mostly managed by males and this finding is in line with the finding of Habte (2019). About75.6\% of the total households, $77 \%$ of indigenous chicken owner households, $77 \%$ exotic chicken owner households and $58.3 \%$ of both exotic sand indigenous chicken owner households were married. About $68.1 \%$ of total households, $71.2 \%$ of indigenous chicken owner households, $60.6 \%$ of exotic chicken owner households and $83.3 \%$ of both exotic and indigenous chicken owner households were protestant religion followers (Table 3.1).

Table 3.1. Demographic characteristics of households- categorical variables

\begin{tabular}{lllll}
\hline Household & Overall sample & Indigenous & Exotic breed & Both breeds
\end{tabular}




\begin{tabular}{|c|c|c|c|c|c|c|c|c|c|}
\hline \multicolumn{2}{|c|}{ characteristics } & \multicolumn{5}{|c|}{ breed } & \multirow[b]{2}{*}{$\%$} & \multirow[b]{2}{*}{ Frequency } & \multirow[b]{2}{*}{$\%$} \\
\hline & & Frequency & $\%$ & Frequency & $\%$ & Frequency & & & \\
\hline \multirow{4}{*}{ Sex } & Male & 139 & 86.9 & 74 & 85 & 54 & 88.5 & 11 & 91.6 \\
\hline & Female & 21 & 13.1 & 13 & 15 & 7 & 11.5 & 1 & 8.4 \\
\hline & Married & 121 & 75.6 & 67 & 77 & 47 & 77 & 7 & 58.3 \\
\hline & Single & 17 & 10.6 & 10 & 11.5 & 3 & 4.9 & 4 & 33.3 \\
\hline \multirow{2}{*}{$\begin{array}{l}\text { Marital } \\
\text { status }\end{array}$} & Divorced & 20 & 12.5 & 9 & 10.3 & 11 & 18 & 0 & 0 \\
\hline & Widowed & 2 & 1.3 & 1 & 1.1 & 0 & 0 & 1 & 8.3 \\
\hline \multirow{3}{*}{ Religion } & Protestant & 109 & 68.1 & 62 & 71.2 & 37 & 60.6 & 10 & 83.3 \\
\hline & Orthodox & 27 & 16.9 & 12 & 13.9 & 13 & 21.3 & 2 & 16.7 \\
\hline & Catholic & 24 & 15 & 13 & 14.9 & 11 & 18 & 0 & 0 \\
\hline
\end{tabular}

\subsection{Socioeconomics and demographic characteristics- continuous variables}

The mean age of total households, indigenous chicken breed owner households, exotic chicken owner households and both indigenous and exotic chicken owner households were 45.11, 45.7, 44.7 and 42.7 years respectively. This mean age is less than Habte (2019) which was 49 years and higher than Melaku (2016) which was 42.7 years. The overall mean years of schooling of households, indigenous chicken owner households, exotic chicken owner households and both indigenous and exotic chicken owner households were $5.1,4.8,5.4$ and 6.2 years of formal schooling respectively. The mean age of indigenous chicken breed owner households was less than the others. However, education level of households helps them to acquire knowledge on poultry production and associated technologies for enhanced production. The mean family size of the total sample, indigenous chicken owner households, exotic chicken owner households and both indigenous and exotic chicken owner households were 5.5, 5.6, 5.5 and 5.7 members respectively. This finding is lower than that of Aman et al (2020) finding of 6.8 members per household and is greater than southern nations nationalities people regional state average of 4.9 and the national average of 4.3 (CSA, 2007). It is believed that higher family size increases labor force requirement in poultry production. The mean livestock including chicken population of the total households, indigenous chicken owner households, exotic chicken owner households and both indigenous and exotic chicken owner households were 3.7, 3.7, 3.7 and 3.25 Tropical Livestock Unit (TLU) respectively. 
The average off farm annual income of the total households, indigenous chicken owner households, exotic chicken owner households and both exotic and indigenous chicken owner households were 3567, 2168, 4898 and 6942 Ethiopian Birr ${ }^{1}$ respectively (Table $3.2)$.

Table 3.2. Socioeconomic and demographic characteristics- continuous variables

\begin{tabular}{|c|c|c|c|c|c|c|c|c|}
\hline \multirow[b]{2}{*}{ Variables } & \multicolumn{2}{|c|}{$\begin{array}{l}\text { Overall sample } \\
(\mathrm{N}=160)\end{array}$} & \multicolumn{2}{|c|}{$\begin{array}{l}\text { Indigenous } \\
\text { breeds }(\mathrm{N}=87)\end{array}$} & \multicolumn{2}{|c|}{$\begin{array}{l}\text { Exotic breeds } \\
(\mathrm{N}=61)\end{array}$} & \multicolumn{2}{|c|}{$\begin{array}{l}\text { Both breeds } \\
(\mathrm{N}=12)\end{array}$} \\
\hline & Mean & St. Dev & Mean & St. Dev & Mean & St. Dev & Mean & St. Dev \\
\hline Age & 45.11 & 10.9 & 45.7 & 11.6 & 44.7 & 10.0 & 42.7 & 10.0 \\
\hline Family size & 5.5 & 2.9 & 5.6 & 3.0 & 5.5 & 3.0 & 5.66 & 1.77 \\
\hline Education level & 5.1 & 2.8 & 4.8 & 2.2 & 5.4 & 3.1 & 6.16 & 4.28 \\
\hline Livestock(TLU) & 3.7 & 4.1 & 3.7 & 3.8 & 3.7 & 4.4 & 3.25 & 4.19 \\
\hline Flock size (TLU) & 0.01 & 0.08 & 0.5 & 0.5 & 0.8 & 0.1 & 0.084 & 0.066 \\
\hline Off -farm income (Birr) & 3,567 & - & 2,168 & - & 4,898 & - & 6,942 & - \\
\hline
\end{tabular}

\subsection{Institutional characteristics of households}

About $95 \%$ of total chicken owner households, $100 \%$ of indigenous chicken owner households, $88.5 \%$ of exotic chicken owner household and $91.6 \%$ of both indigenous and exotic chicken owner households did not have separate chicken houses at day time but they used perches in kitchen or perches in livestock house at night as enclosure. The rest households do have separated chicken houses because their exotic flock size was relatively larger than other households. About $62 \%$ of total chicken owner households, $65.5 \%$ of indigenous chicken owner households, $50.8 \%$ exotic chicken owner households and $91.6 \%$ of both indigenous and exotic chicken owner households got veterinary services directly or indirectly. Discussion with groups and key informants revealed that veterinary services are either unavailable or very expensive to afford. In most cases chicken owner households opt for traditional ways of treating the sick and ill chickens. On the other hand, discussion

\footnotetext{
${ }^{1} 1 \$$ US Dollar was equivalent to 40 Ethiopian Birr during data collection period.
} 
results claimed that indigenous chicken breed have highest resistance to disease compared with exotic chicken breeds.

About $57.5 \%$ of the total chicken owner households, $50.5 \%$ of indigenous chicken owner households, $60.6 \%$ of exotic chicken owner households and $91.6 \%$ of both indigenous and exotic chicken owner households had supplied feeds to their chicken. Key informants interview and focus group discussion result pointed out that it was very difficult to get the ration recommended because the ration are either unavailable or very expensive. Households therefore supplied unrationed feeds such as grains of maize, wheat and other crops and the supply were not scheduled but whenever available. Thus chicken breeds are forced to scavenge and discussion output indicated that scavenging ability of indigenous chicken breed is higher than exotic chicken breeds. This finding coincides with the findings of Fekadu (2018) and Aman et al (2020). About 87\% of total chicken owner households, $99 \%$ of indigenous chicken owner households, $69 \%$ of exotic chicken owner households and $92 \%$ of both indigenous and exotic chicken owner households did not utilize credit for either start up or for management of the chicken flocks (Table 3.3). However, credit is very important for smallholder farmers either to start up new poultry chicken farms or to manage and enhance already existing chicken flocks.

Table 3.3. Institutional characteristics of households

\begin{tabular}{llllllllll}
\hline \multirow{2}{*}{ Variables } & & \multicolumn{2}{c}{ Overall sample } & \multicolumn{2}{c}{ Indigenous breeds } & Exotic breeds & \multicolumn{2}{c}{ Both breeds } \\
\cline { 3 - 9 } & & Frequency & $\%$ & Frequency & $\%$ & Frequency & $\%$ & Frequency & $\%$ \\
\hline $\begin{array}{l}\text { Use of } \\
\text { credit }\end{array}$ & Use & 21 & 13.1 & 1 & 1.1 & 19 & 31.1 & 1 & 8.3 \\
& Not use & 139 & 86.9 & 86 & 98.9 & 42 & 68.9 & 11 & 91.7 \\
$\begin{array}{l}\text { Supply } \\
\text { feeds }\end{array}$ & Yes & 92 & 57.5 & 44 & 50.5 & 37 & 60.6 & 11 & 91.6 \\
& No & 68 & 42.5 & 43 & 49.5 & 24 & 39.4 & 1 & 8.4 \\
$\begin{array}{l}\text { Chicken } \\
\text { house }\end{array}$ & Yes & 8 & 5 & 0 & 0.00 & 7 & 11.5 & 1 & 8.4 \\
& No & 152 & 95 & 87 & 100 & 54 & 88.5 & 11 & 91.6 \\
$\begin{array}{l}\text { Health } \\
\text { facilities }\end{array}$ & Yes & 99 & 61.9 & 57 & 65.5 & 31 & 50.8 & 11 & 91.6 \\
& No & 61 & 38.1 & 30 & 34.5 & 30 & 49.2 & 1 & 8.4 \\
\hline
\end{tabular}




\subsection{Chicken breeds related characteristics}

About $59 \%$ of total chicken owner households, $89 \%$ of indigenous chicken owner households, $18 \%$ of exotic chicken owner households and $50 \%$ of both indigenous and exotic chicken owner households reported that the mothering ability of their breeds were high(Table 3.4). This finding is similar with finding of Zelalem et al (2019). About $58 \%$ of total chicken owner households, $87 \%$ of indigenous chicken owner households, $18 \%$ of exotic chicken owner households and $50 \%$ of both indigenous and exotic chicken owner households claimed that the productivity of their breeds were medium. But $74 \%$ of exotic chicken owner households said that the productivity of exotic breeds was high, which was measured by both egg and meat production. About $75 \%$ of exotic chicken owner households said that egg production per year per chicken was high and $87 \%$ of indigenous chicken owner households reported that egg production per year per chicken was low. White colored egg was preferred by $62.5 \%$ of households, $92 \%$ of indigenous chicken owner households but red colored egg was preferred by $69 \%$ of exotic chicken owner households. About $61 \%$ of total households and $99 \%$ of indigenous chicken owner households perceived that the egg size was small but $82 \%$ of exotic chicken owner households perceived that the egg size was big. This finding is in agreement with the finding of Habte (2019).

About $76 \%$ of total chicken owner households, $86 \%$ of indigenous chicken owner households, $57 \%$ of exotic chicken owner households and $92 \%$ of both indigenous and exotic chicken owner households preferred red feather color as one of the criteria used for

poultry chicken breeds choices. Red color is more preferable than other colors for both ecotypes which are similar with the finding of Addis (2014). About 54\% of total chicken owner households, $54 \%$ of indigenous chicken owner households, $59 \%$ of exotic chicken owner households preferred single comb type chicken breeds. However, discussion finding revealed that double comb type is dominant for indigenous poultry chicken breeds and exotic chicken breeds are known for their single comb type. About $67 \%$ of total chicken owner households, $87 \%$ of indigenous chicken owner households and $92 \%$ of both indigenous and exotic chicken owner households reported that meat and egg tastes were 
good but $67 \%$ of exotic chicken owner households reported that meat and egg tastes were poor. This finding is in agreement with finding of Nigussie et al (2010).

Participants of focus group discussion and key informants ranked their preference using pairwise raking methods concerning chicken breeds traits and ranked mothering ability $\left(1^{\text {st }}\right)$, scavenging ability $\left(2^{\text {nd }}\right)$, taste of meat and egg $\left(3^{\text {rd }}\right)$ and egg size $\left(4^{\text {th }}\right)$ for indigenous chicken breeds. On the other hand, they ranked growth rate $\left(1^{\text {st }}\right)$, number of eggs per chicken per year $\left(2^{\text {nd }}\right)$ and size of egg $\left(3^{\text {rd }}\right)$ for exotic chicken breeds. The finding coincides with the finding of Berhanu et al (2020). When productive traits was compared among indigenous and exotic chicken breeds, growth rate of exotic breed was ranked first, taste of meat and egg was ranked first for indigenous chicken breeds compared with exotic poultry chicken breeds and number of eggs per chicken per year was ranked first for exotic poultry chicken breed than indigenous chicken breeds.

Table 3.4. Chicken breeds related characteristics

\begin{tabular}{|c|c|c|c|c|c|c|c|c|c|}
\hline \multirow[t]{2}{*}{ Variables } & & \multicolumn{2}{|c|}{ Overall sample } & \multicolumn{2}{|c|}{ Indigenous breeds } & \multicolumn{2}{|c|}{ Exotic breeds } & \multicolumn{2}{|l|}{ Both breeds } \\
\hline & & Frequency & $\%$ & Frequency & $\%$ & Frequency & $\%$ & Frequency & $\%$ \\
\hline \multirow{4}{*}{$\begin{array}{l}\text { Disease } \\
\text { resistance }\end{array}$} & Low & 26 & 16.3 & 0 & 0 & 25 & 40.9 & 1 & 8.3 \\
\hline & Medium & 30 & 18.8 & 0 & 0 & 20 & 32.7 & 10 & 83.3 \\
\hline & High & 94 & 58.8 & 82 & 94.3 & 11 & 18 & 1 & 8.3 \\
\hline & Undefined & 10 & 6.3 & 5 & 5.7 & 5 & 8.2 & 0 & 0 \\
\hline \multirow[t]{2}{*}{ Egg size } & Big & 62 & 38.8 & 1 & 1.1 & 50 & 82 & 11 & 91.6 \\
\hline & Small & 98 & 61.3 & 86 & 98.9 & 11 & 18 & 1 & 8.4 \\
\hline \multirow{2}{*}{$\begin{array}{l}\text { Eggs/year/ } \\
\text { chicken }\end{array}$} & High & 68 & 42.5 & 15 & 17.2 & 46 & 75 & 7 & 58 \\
\hline & Low & 92 & 57.5 & 72 & 82.8 & 15 & 25 & 5 & 42 \\
\hline \multirow[t]{2}{*}{ Egg color } & Red & 60 & 37.5 & 7 & 8 & 42 & 69 & 11 & 91.6 \\
\hline & White & 100 & 62.5 & 80 & 92 & 19 & 31 & 1 & 8.4 \\
\hline \multirow{3}{*}{$\begin{array}{l}\text { Mothering } \\
\text { ability }\end{array}$} & Low & 1 & 0.6 & 0 & 0 & 0 & 0 & 1 & 8 \\
\hline & Medium & 5 & 3.1 & 5 & 5.7 & 0 & 0 & 0 & 0 \\
\hline & High & 94 & 58.8 & 77 & 88.5 & 11 & 18 & 6 & 50 \\
\hline
\end{tabular}




\begin{tabular}{|c|c|c|c|c|c|c|c|c|c|}
\hline & Undefined & 60 & 37.5 & 5 & 5.7 & 50 & 82 & 5 & 42 \\
\hline \multirow{2}{*}{$\begin{array}{l}\text { Meat and } \\
\text { egg taste }\end{array}$} & Good & 107 & 66.9 & 76 & 87 & 20 & 33 & 11 & 91.6 \\
\hline & Poor & 53 & 33.1 & 11 & 13 & 41 & 67 & 1 & 8.4 \\
\hline \multirow{3}{*}{$\begin{array}{l}\text { Feather } \\
\text { color }\end{array}$} & Red & 121 & 75.6 & 75 & 86 & 35 & 57 & 11 & 91.6 \\
\hline & Brown & 30 & 18.8 & 5 & 6 & 25 & 41 & 0 & 0 \\
\hline & Teterima & 9 & 5.6 & 7 & 8 & 1 & 2 & 1 & 8.4 \\
\hline \multirow[t]{2}{*}{ Comb type } & Single & 86 & 53.8 & 47 & 54 & 36 & 59 & 3 & 25 \\
\hline & Double & 74 & 46.3 & 40 & 46 & 25 & 31 & 9 & 75 \\
\hline \multirow{3}{*}{$\begin{array}{l}\text { Growth } \\
\text { rate }\end{array}$} & Low & 16 & 10 & 15 & 17 & 0 & 0 & 1 & 8 \\
\hline & Medium & 83 & 51.9 & 62 & 71 & 16 & 26 & 5 & 42 \\
\hline & High & 61 & 38.1 & 10 & 12 & 45 & 74 & 6 & 50 \\
\hline \multirow{3}{*}{$\begin{array}{l}\text { Productivity } \\
\text { level }\end{array}$} & Medium & 93 & 58.1 & 76 & 87 & 11 & 18 & 6 & 50 \\
\hline & High & 57 & 35.6 & 6 & 7 & 45 & 74 & 6 & 50 \\
\hline & Undefined & 10 & 6.3 & 5 & 6 & 5 & 8 & 0 & 0 \\
\hline
\end{tabular}

\subsection{Functions of poultry chicken keeping}

As indicated in Table 3.5, 73\% of the total chicken owner households, $61 \%$ of indigenous chicken owner households, $96 \%$ of exotic chicken owner households and $42 \%$ of both indigenous and exotic chicken owner households keep chicken breeds for generating and augmenting household income but $50 \%$ of both indigenous and exotic chicken owner households keep both breeds for breeding purpose. They said that they keep both because each breed has its own advantage and breeding bring the quality of one breed to another and help them as replacement. This finding is in line with the findings of Nigussie et al (2010b) and Berhanu et al (2020) and in disagreement with Habte (2019). If the objective of keeping chicken breeds was as the source of income, they should give due attention on keeping high yielding exotic breeds but the finding above does not support this. Discussion with farmers, participants of focus group discussion and key informants pointed out that farmers want to keep exotic breeds but they lack credit to build chicken houses, establish veterinary services, prepare chicken ration and purchase refrigerators, among others which are highly demanded by exotic chicken breeds. 
Table 3.5. Functions of poultry chicken keeping

\begin{tabular}{lllllllll}
\hline \multirow{2}{*}{ Functions of poultry } & \multicolumn{2}{l}{ Overall sample } & $\begin{array}{l}\text { Indigenous } \\
\text { breeds }\end{array}$ & \multicolumn{2}{c}{ Exotic breeds } & \multicolumn{2}{c}{ Both breeds } \\
\cline { 2 - 8 } & Frequency & $\%$ & Frequency & $\%$ & Frequency & $\%$ & Frequency & \% \\
\hline Egg for home consumption & 20 & 12.5 & 18 & 21 & 1 & 2 & 1 & 8.3 \\
Meat for home consumption & 1 & 0.6 & 0 & 0 & 1 & 2 & 0 & 0 \\
Source of income & 117 & 73.1 & 53 & 61 & 59 & 96 & 5 & 41.6 \\
Replacement & 16 & 10 & 10 & 11 & 0 & 0 & 6 & 50 \\
Job opportunities & 6 & 3.8 & 6 & 7 & 0 & 0 & 0 & 0 \\
\hline
\end{tabular}

\subsection{Determinants of Rural Households' Poultry Chicken Breeds Choice}

Before running multinomial model, it was checked for multicollinearity and heteroscedasticity misspecification. The values for variance inflation factor of continuous variables and contingency coefficient for categorical variables were less than 10 and 0.75 respectively indicating that there was no series multicollinearity. Spearman's rank correlation test indicates that there was no heteroscedasticity among the variables. The use of Housman test to validate the assumption of Independence of Irrelevant Alternatives (IIA) failed to reject the null hypothesis on the IIA assumption at 95\% confident level. This suggests that multinomial logit model was appropriate to identify determinants of rural households' choice of poultry chicken breeds keeping in Ethiopia. The final model was significantly fit to precede the estimation $\left(\chi^{2}{ }_{44}=285.82\right)$. McFadden's pseudo $\mathrm{R}^{2}$ value of 93\% suggests that the goodness of fit of the model is adequate (Pituch and Stevens, 2016).

As indicated in Table 3.6., out of 14 independent variables entered into Multinomial model, 8 of them such as age, education, mothering ability, breed productivity, resistance to diseases, scavenging ability, growth rate and feather color determined the choice of poultry chicken breeds among rural households in Ethiopia.

Age of household head was positively and significantly determined the choice of exotic poultry chicken breed in comparison with choice of indigenous chicken breed at less than $1 \%$ significant level. Keeping other variables kept constant, the log odd indicates that a year increase in age of a household head increases the probability of keeping exotic chicken breed by 1.08 as compared with keeping indigenous chicken breeds. This further 
shows that the younger the household head the more likely exotic chicken breed to be chosen as compared with indigenous chicken breeds. This implies that if extension system is to promote exotic chicken breeds in the rural areas of the country, they should target young aged household heads as they are innovators in relation to old aged household heads.

Education of household head was negatively and significantly determined the choice of exotic chicken breeds in comparison with indigenous chicken breeds at less than $1 \%$ significant level. The marginal effect indicates that a year decrease in formal schooling of a household head increases the probability of choosing indigenous chicken breeds by 0.8 , ceteris paribus. This implies that future attempt to promote exotic chicken breeds in rural areas they should give due attention for relatively educated household heads because education enhances their understandings and market orientation.

The mothering abilities of breeds was negatively and significantly determined exotic chicken breeds choice compared with indigenous chicken breeds at less than $1 \%$ significant level. Holding other variables at constant, the odds ratio in favor of indigenous breeds indicate that a unit increase in searching for mothering ability of households increases the choose of indigenous chicken breeds by 1.6 when compared with exotic chicken breeds choice. The implication is that if the objective of keeping poultry chicken breeds is for enhancing mothering ability, development intervention should focus on indigenous chicken breeds.

Table 3.6.Multinomial logit model estimation for determinants of rural household choice of poultry chicken breeds

\begin{tabular}{lllll}
\hline \multirow{2}{*}{ Variables } & \multicolumn{2}{l}{ Exotic poultry chicken breed } & \multicolumn{2}{l}{ Both poultry chicken breeds } \\
\cline { 2 - 5 } & $\boldsymbol{\beta}$ & $\operatorname{Exp}(\boldsymbol{\beta})$ & $\boldsymbol{\beta}$ & $\mathbf{E x p}(\boldsymbol{\beta})$ \\
\hline Intercept & -59.9 & - & -566.7 & - \\
AGE & $0.074 * * *$ & 1.08 & 5.06 & 1.5 \\
EDU & $0.23 * * *$ & 0.799 & -5.1 & 0.006 \\
{$[\mathrm{SEX}=0]$} & -0.49 & 0.645 & -3.38 & 0.034 \\
{$[\mathrm{MOT}=0]$} & $-16.5 * * *$ & 6.6 & $119.68 * * *$ & 9.43 \\
{$[\mathrm{MOT}=1]$} & $-53.5 * * *$ & 5.9 & 120.65 & 2.49 \\
{$[\mathrm{MOT}=2]$} & $-15.67 * * *$ & 1.6 & -106.75 & 4.37 \\
{$[\mathrm{PRO}=1]$} & $14.4 * * *$ & 1.7 & 10.93 & 5.54
\end{tabular}




$\begin{array}{lllll}{[\mathrm{PRO}=2]} & 16.24 * * * & 1.1 & -299.92 * * * & 5.56 \\ {[\mathrm{RES}=0]} & -67.02 * & 7.83 & 461.55 * * * & 3.1 \\ {[\mathrm{RES}=1]} & -17.16 * & 3.53 & 237.36 * * * & 1.2 \\ {[\mathrm{SCA}=0]} & 55.81 * * & 1.7 & 277.03 & 1.3 \\ {[\mathrm{SCA}=1]} & 3.24 * * * & 2.5 & 371.4 * * & 0.9 \\ {[\mathrm{GRR}=0]} & 2.87 * * * & 1.7 & 401.8 * * & 0.7 \\ {[\mathrm{GRR}=1]} & 3.35 * * * & 28.42 & 354.17 * * & 6.4 \\ {[\mathrm{EGN}=0} & 37.2 & 1.4 & -21.6 & 4.2 \\ {[\mathrm{MTAS}=0]} & -1.1 & 0.34 & -19.8 & 2.43 \\ {[\mathrm{FED}=0]} & -0.72 & 0.49 & -56.13 & 4.18 \\ {[\mathrm{HEA}=0]} & -0.23 & 0.79 & -28.18 & 5.83 \\ {[\mathrm{COL}=0]} & 36.76 * * & 0.9 & -32.278 * * * & 9.58 \\ {[\mathrm{COL}=1]} & 76.54 & 0.89 & -129.61 & 5.13\end{array}$

The reference category was Indigenous poultry chicken breed

Productivity level of breeds was positively and significantly determined exotic chicken breed choice as compared with indigenous chicken breeds at less than $1 \%$ significant level. The marginal effect shows that a unit increase in search for productivity trait of chicken breed increases the choice of exotic chicken breed by 1.7 as compared with indigenous chicken breed choice, ceteris paribus. The odd ratio coefficients were $(1.7,1.68)$ in medium and (1.1), (28.42), and (1.4) in high rate respectively. The finding coincides with finding of Habte (2019). If the objective of choosing among chicken breed is for productivity purpose, it should be exotic chicken breed which are prepared most.

Resistance to disease of breeds was negatively and significantly determined the choice of exotic chicken breeds as compared with indigenous chicken breed at less than $10 \%$ significant level. Ceteris paribus, the marginal effect indicates that a unit increase in searching for chicken breed traits for disease resistance decreases the choice of exotic chicken breeds by 7.83 in comparison with indigenous chicken breeds. In terms of disease resistance the exotic poultry chicken breed in various rate categories (low, medium and high) were preferred less and indigenous chicken breeds are chosen if the objective of keeping the breeds is for disease resistance. Thus this finding is similar with the finding of Zelalem et al (2019).

In general, the model finding supports the finding of descriptive statistics, focus group discussion and key informants interview. If the objectives of keeping chicken breeds are 
for disease resistance, mothering ability and scavenging from the environment in the absence of improved feed supply, indigenous chicken breeds are more preferred than exotic chicken breeds whereas if the purpose of keeping chicken breeds are for productivity, growth and income generation, exotic chicken breeds are preferred compared to indigenous chicken breeds. If the objective of keeping is to maintain the best qualities of both indigenous and exotic chicken breeds, keeping both types is preferred as breeding occurs while both of them are living together.

\section{Conclusion and Recommendations}

The study was conducted in Damot Pulasa district of Wolaita zone in Ethiopia to determine rural households' choice of keeping poultry chicken breeds. Data were collected from 160 randomly selected households and were analyzed using both descriptive and multinomial logit model. About $54.37 \%$ of the households owned indigenous poultry chicken breed, 38\% owned exotic poultry chicken breed and $7.5 \%$ owned both indigenous and exotic poultry chicken breeds. However, households reported that the main purpose of keeping poultry chicken breed was to generate income. Households replied they own large number of indigenous chicken breeds because they do not have adequate finance to fulfill all requirements that exotic chicken breeds demand. Finding from descriptive statistics, focus group discussion, key informant interview and empirical results indicated that age of household head, education level of household head, mothering ability of breeds, productivity of breeds, resistance to diseases, scavenging ability of breeds, growth rate of breeds and feather color determined the probability of choosing either of the breeds. In particular, indigenous chicken breeds were preferred for their mothering ability $\left(1^{\text {st }}\right)$, scavenging ability $\left(2^{\text {nd }}\right)$, taste of meat and egg $\left(3^{\text {rd }}\right)$ and egg size $\left(4^{\text {th }}\right)$ and that of exotic chicken breeds were ranked for growth rate $\left(1^{\text {st }}\right)$, number of eggs per chicken per year $\left(2^{\text {nd }}\right)$ and size of egg $\left(3^{\text {rd }}\right)$.

If extension system is to promote exotic chicken breeds in the rural areas of the country, they should target young aged household heads as they are innovators in relation to old aged household heads and look for relatively educated household heads because education enhances their understandings and market orientation. Adequate finance is an important institutional factor and credit use system should be enhanced at affordable size, poultry 
chicken veterinary services should be available and affordable, improved feed ratio enhanced through training how to prepare locally available ingredients. If extension system is to promote indigenous chicken breeds, they should cross breed indigenous with exotic to maintain mothering ability, disease resistance quality, meat and egg taste and improve chicken management system such as supplying improved ratio, houses and veterinary services, among others.

\section{Data availability}

The data used to support the findings of this study are available from the corresponding authors upon request.

\section{Conflict of interest}

No potential conflict of interest was reported by the authors.

\section{Acknowledgements}

The authors would like to thank Damote Pulasa district agricultural office staff members for providing the required data and kebele development agents who participated in data collection. Above all, we acknowledge smallholder farmers who devoted their time and willingly gave their responses to make the study to this end.

\section{References}

Addis Getu, (2014). Review work on farmer trite preferences for their breeding objectives of local chicken ecotypes in Ethiopia.

Adebambo O., Adebambo A.,Adeleke M.,Adeleye A.,Adetunji A., Ajayi F., Akinola W., Alabi O., Bamidele O., Dessie T., Ikeobi C., Ogundu U., Ojoawo H., Osinbowale D., Ozoje M.,Peters S., Soniya B., Wheto M., and Yakubu A. (2018). Genetic conservation through effective utilization of the improved indigenous chicken breeds by rural households in Nigeria. Proceedings of the World Congress on Genetics Applied to Livestock Production, Auckland, New Zealand, February 11-16, 2018. Paper No: 1117.

Alemayehu A, Yilma T, Shibeshi\& Z, Workneh T (2015). Village Chicken Production Systems in Selected Areas of Benishangul - Gumuz, Western Ethiopia.

Aman G., Fitsum T., Mesfin M., Addisu J. \& Bereket Z. (2020). Assessment of Village Chicken Production Systems in Kambata Tambaro and Wolaita Zones, SNNPR, Ethiopia. Global Journal of Science Frontier Research.

Berhanu B., Aberra M., Sandip B., Wondmeneh E. and Tadelle Dessie (2020). Farmers' preferences towards breeding objective for indigenous chickens in different agroecologies of Ethiopia. African Journal of Agricultural Research. 
Brown, M.M., Alenyorege, B., Teye, G.A., Roessler, R., (2017). Phenotypic diversity, major genes and production potential of local chickens and guinea fowl in Tamale, northern Ghana. Asian- Australasian Journal of Animal Science, 30, 1372-1381.

CSA (2007). Population and Housing Census of Ethiopia. Central Statistical Authority, April 2012, Addis Ababa, Ethiopia.

CSA (2017). Ethiopian agricultural sample enumeration Statistical report on livestock, Addis Ababa, Ethiopia.

Dessie, T., Markos, S., and Belay, B., (2017). Village chicken breeding practices, objectives and farmers' trait preferences in western zone of Tigray, Northern Ethiopia. E3 Journal of Agricultural Research Development, 6, 1-11.

Evan Morris (1998). Small sample size formula of hyper geometric.

Fekadu T. (2019). Indigenous chicken farmers traits preferences, breeding objectives and marketing systems in South west Ethiopia. Unpublished paper.

Fulas H., Yohannis H., Yobsan T.and Abriham K. (2018). Review on Challenges and Opportunities of Poultry Breeds. Journal of dairy and veterinary sciences.

Greene, W. H. (2018). Econometric Analysis. 8th ed. New York: Pearson.

Greene, W.H., (2003). Econometric Analysis, 5th Edition. Prentice Hall.Inc, London. $1026 \mathrm{p}$.

Habte A. (2019). Characterization of chicken production systems and on farm evaluation of introduced exotic chicken breeds in Amhara region. Unpublished paper.

Mahendra Kumar Padhi (2016). Importance of indigenous breeds of chicken for rural economy and their improvements for higher production performance. Hindawi Publishing Corporation.

Melaku T. (2016). On-farm phenotypic characterization of indigenous chicken population and their production system at Borena, Wogdi and LegamboWoredas in South Wollo, Ethiopia. MSc Thesis, College of Agriculture, Haramaya University, Haramaya, Ethiopia, P. 54.

Nigussie, D., Tadelle D, Waaij L H and Arendonk J A M, (2010). Production objectives and trait preferences of village poultry producers of Ethiopia: implications for designing breeding schemes utilizing indigenous chicken genetic resources.

Psifidi, A., Banos, G., Matika, O., Desta, T. T., Bettridge, J., Hume, D. A., Kaiser, P. (2016). Genome-wide association studies of immune, disease and production traits in indigenous chicken ecotypes. Genetics Selection Evolution, 48(1).

Simegnew T., Fessiha m., Yeshiwas T., and Molla H. (2019). Determinants of adoption of exotic poultry breeds among smallholder poultry producers in North Western Amhara Region, Ethiopia. Global Journal of Agricultural Economics and Econometrics.

Tamirat D (2015). Overview and background paper on Ethiopia's poultry sector Relevance for HPAI research in Ethiopia. ILRI report 17.

Tlou G. Letlhogonolo S., Mohammed H, and Monnye M. (2020). Local Chicken Breeds of Africa: Their Description, Uses and Conservation Methods. MDPI animal journals.

WoFED (2020).Wolaita Zone Finance and Economic development Annual report of statistical abstract Ethiopia, Wolaita Sodo.

Wong, J. T., de Bruyn, J., Bagnol, B., Grieve, H., Li, M., Pym, R., and Alders, R. G. (2017). Small-scale poultry and food security in resource-poor settings: A review. Global Food Security, 15, 43-52. 
Yakubu, A., Dahloum, L. and Gimba, E.G. (2019). Smallholder cattle farmers' breeding practices and trait preferences in a tropical guinea savanna agro-ecological zone. Tropical Animal Health and Production.

Zelalem G. Terfa, S. Garikipati, Girma T. Kassie, Tadelle Dessie, R.M. Christly (2020). Understanding farmers' preference for traits of chickens in rural Ethiopia. Journal of International association of agricultural economics. 